\title{
Primary failure of eruption (PFE): a systematic review
}

\author{
Marcel Hanisch ${ }^{1 *}$, Lale Hanisch², Johannes Kleinheinz ${ }^{1}$ and Susanne Jung ${ }^{1}$
}

\begin{abstract}
Background: Primary failure of eruption (PFE) is a rare disease defined as incomplete tooth eruption despite the presence of a clear eruption pathway. Orthodontic extrusion is not feasible in this case because it results in ankylosis of teeth. To the best of our knowledge, besides the study of Ahmad et al. (Eur J Orthod 28:535-540, 2006), no study has systematically analysed the clinical features of and factors associated with PFE. Therefore, the aim of this study was to systematically evaluate the current literature (from 2006 to 2017) for new insights and developments on the aetiology, diagnosis, genetics, and treatment options of PFE.

Methods: Following the PRISMA guidelines, a systematic search was performed using the PubMed/Medline database for studies reporting on PFE. The following terms were used: "primary failure of tooth eruption", "primary failure of eruption", "tooth eruption failure", and "PFE".

Results: Overall, 17 articles reporting clinical data of 314 patients were identified. In all patients, the molars were affected. In 81 reported cases, both the molars and the premolars were affected by PFE. Further, 38 patients' primary teeth were also affected. In 27 patients, no family members were affected. Additional dental anomalies were observed in 39 patients. A total of 51 different variants of the PTHIR gene associated with PFE were recorded.

Conclusions: Infraocclusion of the posterior teeth, especially if both sides are affected, is the hallmark of PFE. If a patient is affected by PFE, all teeth distal to the most mesial tooth are also affected by PFE. Primary teeth can also be impacted; however, this may not necessarily occur. If a patient is suspected of having PFE, a genetic test for mutation in the PTH1R gene should be recommended prior to any orthodontic treatment to avoid ankylosis. Treatment options depend on the patient's age and the clinical situation, and they must be evaluated individually.
\end{abstract}

Keywords: Eruption disorder, Orthodontics, PFE, Primary failure of eruption, PTH1R, Rare diseases, Systematic review

\section{Background}

Primary failure of eruption (PFE) is a rare disease with a prevalence of $0.06 \%$ [1]. PFE is defined as incomplete tooth eruption despite the presence of a clear eruption pathway. The key manifestations of PFE were first described by Proffit and Vig [2]. PFE involves partial or complete noneruption of initially non-ankylosed teeth due to a disturbed eruption mechanism, resulting in a posterior unilateral/bilateral open bite. Orthodontic extrusion is not feasible because this procedure will cause the teeth to become ankylosed. PFE affects both primary and permanent teeth, which may erupt into initial occlusion and then cease to

\footnotetext{
* Correspondence: marcel.hanisch@ukmuenster.de

'Department of Cranio-Maxillofacial Surgery, Research Unit Rare Diseases with Orofacial Manifestations (RDOM), University Hospital Münster,

Albert-Schweitzer-Campus 1, Gebäude W 30, D-48149 Münster, Germany Full list of author information is available at the end of the article
}

erupt further. Posterior teeth are most commonly affected, and typically, all teeth distal to the most mesial affected teeth exhibit the disorder [2].

PFE was further divided into three different types by Frazier-Bowers et al. [3]. In PFE Type I, the mesial to distal teeth show a similar or severe lack of eruption potential, and in Type II, the teeth distal to the most mesial affected tooth show greater but still inadequate eruption potential. Patients affected by both Type I and II PFE are diagnosed as having Type III PFE.

According to Raghoebar et al. [4, 5], localized eruption failure can be categorized into the following: (1) primary retention that is defined as an arrest of the eruption process before the crown has penetrated the oral mucosa and (2) secondary retention that involves cessation of further eruption after the tooth has penetrated the oral mucosa. 
Differential diagnosis must exclude systemic or syndromic disorders such as regional cleidocranial dysplasia, regional odontodysplasia, Albers-Schönberg osteopetrosis, and GAPO syndrome. Table 1 gives an overview of rare diseases marked by tooth eruption disorders.

Furthermore, other eruption failures such as mechanical failures of eruption (MFE) [6] or isolated ankylosis characterized by infraocclusion, immobility, metallic sound on percussion, and radiographic obliteration of the periodontal ligament space must be excluded [7].

Decker et al. [8] showed that a genetic mutation in the PTH1R gene is associated with PFE. The exact mechanism by which PTH1R-mutation leads to PFE is poorly understood [9]. Both animal and human studies have documented that PTHrP, a PTH1R ligand, is essential in the process of tooth eruption [10]. The failure of dental follicle cells to produce PTHrP causes the initially normally developed teeth to get impacted and encapsulated by a bony crypt. The activation of the cAMP/PKA pathway in tooth eruption by either ligand results in progression of tooth development and eruption. Interruption of these pathways results in ankylosis owing to upregulation of the biomineralization of cementoblasts and failure of tooth eruption [11]. Thus, clinical symptoms and confirmed mutation of the PTH1R gene can be used to establish a diagnosis of PFE.

To the best of our knowledge, except the study by Ahmad et al. [12], no study has systematically analysed the clinical and genetic features of PFE and its associated factors. Therefore, the aim of this study was to systematically evaluate the current literature including studies published from 2006 to 2017 for new insights and developments in aetiology, diagnosis, treatment options, and genetics to ensure early corrective diagnosis and treatment of PFE.

Table 1 Rare diseases featuring tooth eruption failure

\begin{tabular}{lll}
\hline Disease name & OMIM number & $\begin{array}{l}\text { Orphanet } \\
\text { number }\end{array}$ \\
\hline $\begin{array}{l}\text { Albers-Schönberg } \\
\text { osteopetrosis }\end{array}$ & 166600 & 53 \\
$\begin{array}{l}\text { Cherubism } \\
\text { Cleidocranial } \\
\text { dysplasia }\end{array}$ & 118400 & 184 \\
$\begin{array}{l}\text { GAPO syndrome } \\
\text { Hypodontia-dysplasia } \\
\text { of nails syndrome }\end{array}$ & 119600,216330 & 1452 \\
$\begin{array}{l}\text { McCune-Albright } \\
\text { syndrome }\end{array}$ & 230740 & 2067 \\
$\begin{array}{l}\text { Nance-Horan syndrome } \\
\begin{array}{l}\text { Oculodental syndrome, } \\
\text { Rutherfurd type }\end{array}\end{array}$ & 189500 & 2228 \\
$\begin{array}{l}\text { Regional odontodysplasia } \\
\text { Osteoglophonic dwarfism }\end{array}$ & 174800 & 562 \\
\hline
\end{tabular}

\section{Methods}

A literature search of the PubMed/Medline database, including all English or German language papers published after the latest systematic review by Ahmad et al. [12] until February 2017 was performed. The reference lists of all relevant articles were also screened manually to identify further potentially relevant articles. The following search terms were used:

- "primary failure of tooth eruption"

- "primary failure of eruption"

- "tooth eruption failure"

- "PFE"

The article types included were case reports, case series, observational studies, review articles, and retrospective studies. Studies with limited data including conference abstracts and letters to journal editors were excluded.

Two calibrated reviewers ( $\mathrm{MH}$ and $\mathrm{LH}$ ) independently conducted the search, study inclusion, and data extraction. Any disagreement between the two reviewers was resolved by discussing with a third reviewer (SJ). According to the PRISMA guidelines [13], all records identified from the database entries were checked for duplicates. After removing the duplicates, abstracts were screened for the eligibility of inclusion. The inclusion criteria were as follows:

1) Absence of a systemic or syndromic cause

2) Clear eruption pathway (no mechanical failure, alveolar bone coronal resorbed) with apparently normal resorption

3) Involvement of the teeth distal to the most mesial affected tooth

4) No evidence of successful orthodontic extrusion of the affected tooth or teeth

5) Confirmed mutation of the PTH1R gene (if data were available)

Subsequently, full-texts were assessed for eligibility, and the references were reviewed for other reports of PFE. Using these references, full texts were assessed for eligibility. Finally, all records were analysed according to the aims of this study. The mode of literature search is summarized in Fig. 1.

\section{Results}

\section{Data selection}

The first literature search of the PubMed database was performed using the keywords listed in the Methods section; this search displayed 291 entries. After removing the duplicates, 168 articles remained; these were subjected to a preselection process by screening their 
abstracts. After the preselection, 135 articles were excluded because they were not published in English or German $(n=10)$, subjects had an associated systemic or syndromic disorder $(n=19)$, coexistence of other kinds of eruption disorders like MFE $(n=30)$, the article was an orthodontic article that did not report on PFE $(n=8)$, the article was about an animal study $(n=4)$, or the article did not report clinical or other data $(n=64)$.

Subsequently, 33 full-length articles were selected; 18 of these were excluded because of the non-involvement of the teeth distal to the most mesial affected tooth $(n=5)$, insufficient or unavailable clinical data $(n=5)$, mechanical failure of eruption $(n=2)$, only the deciduous teeth were affected $(n=2)$, contained the results of in vitro studies $(n=1)$, teeth affected by reaction to orthodontic forces $(n=1)$, existence of a systemic cause $(n=1)$, and no resorption of the coronal alveolar bone $(n=1)$.

Screening of the references from these 15 selected articles led to further inclusion of 4 articles from which 2 were rejected for non-involvement of the teeth distal to the most mesial affected tooth $(n=2)$.

\section{Outcome data}

Finally, 17 articles reporting on PFE were included [3, 6, $8,9,14-26]$. These articles contain case reports $(n=5)$, case series $(n=3)$, observational study $(n=5)$, and retrospective analysis $(n=4)$.

\section{Sex and age distribution}

Overall, 314 patients were studied, with 30 female and 22 male patients. For 262 patients, the sex was not reported.

The ages of 15 female patients and 12 male patients were available; however, the age at the time of diagnosis of PFE was usually unclear. The reported ages of the female patients ranged from 8 to 58 years (mean: 24.6 years), while those of the male patients ranged from 10 to 58 years (mean: 23 years).

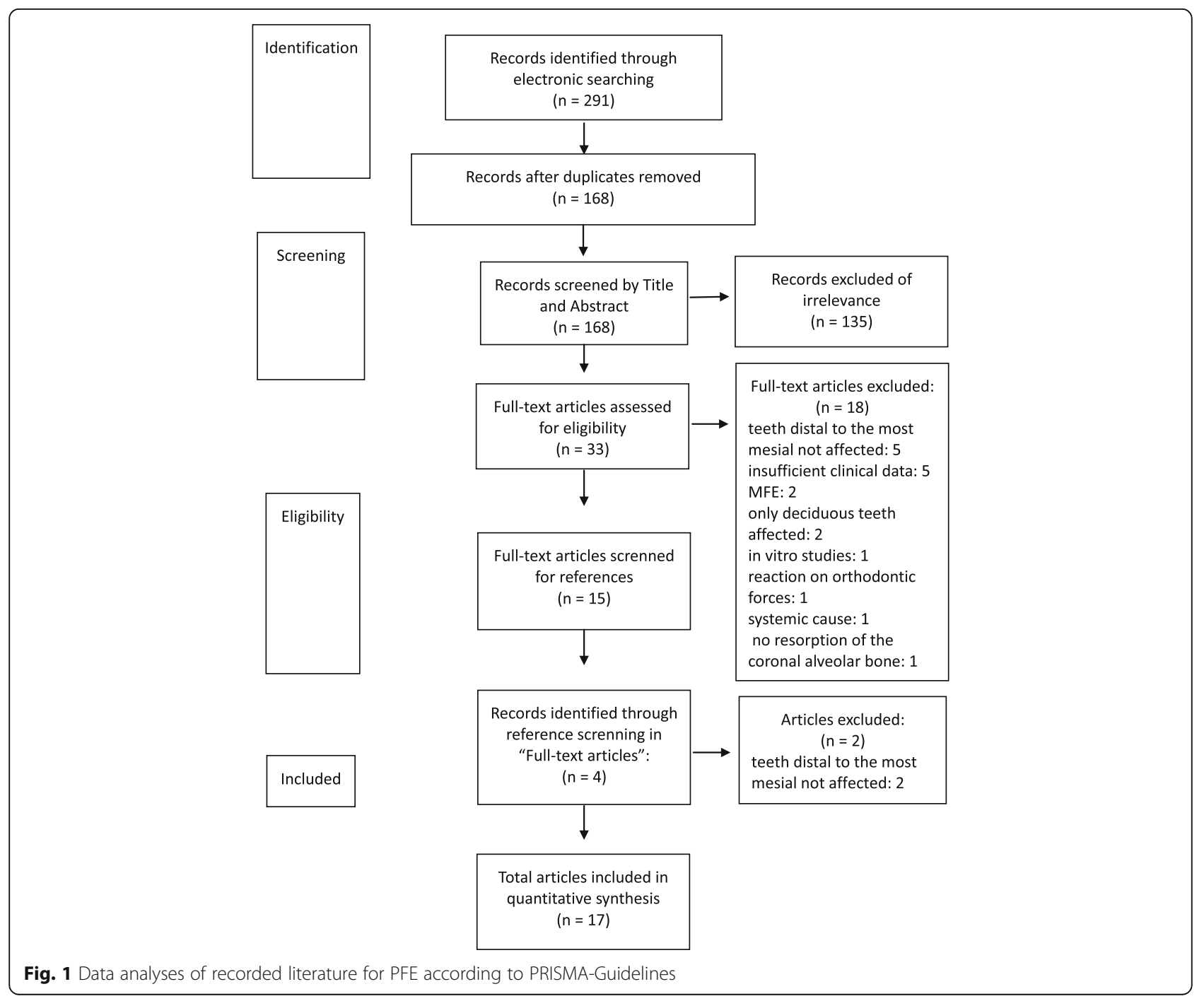




\section{Affected teeth}

In all the reported cases, the molars were affected. In 118 cases, detailed clinical data were available; therefore, we could distinguish whether only molars or molars and premolars were impacted. In 81 of the 118 reported cases, both the molars and the premolars were affected by PFE (68.6\%).

\section{Primary teeth affected by PFE}

In 38 cases $(24.3 \%)$, the primary teeth were affected, while in 118 patients (75.7\%), the deciduous teeth were not affected. Data were unavailable for 158 cases.

\section{Unilateral/bilateral}

Both the right and left sides were affected in 95 patients (64.1\%), while only 1 side was affected in 53 cases (35.9\%). No data were available for 166 patients.

\section{Family history}

In 143 cases (84.1\%), family members were also reported to have PFE. In 27 cases, none of the family members was affected by PFE (15.9\%). In 144 cases, no data about PFE in family members were available.

\section{Types of PFE}

In all, 53 patients $(41.7 \%)$ were classified as PFE Type I, 40, as Type II (31.5\%), and 34, as Type III (26.8\%). For 187 patients, no data were available.

\section{Skeletal class}

PFE with skeletal class I was reported in 2 cases and with class II in 5 cases, while skeletal class III was reported in 27 cases. For 280 patients, no data were available.

\section{Additional dental anomalies}

In 39 cases, additional dental anomalies were described. These included alterations in the root morphology $(n=11)$, impacted teeth $(n=10)$, delayed eruption of further teeth $(n=6)$, hypodontia $(n=5)$, hyperdontia $(n=3)$, transposition of teeth $(n=2)$, peg-shaped teeth $(n=1)$, and MFE $(n=1)$. One author also reported alterations in the root morphology, hyperdontia, and hypercementosis in his study involving 15 patients [6]. In 70 cases, no further dental anomalies were reported, while no details regarding these data were available for 190 cases.

\section{Treatment}

The treatment performed was reported in 22 cases, namely extraction of the affected teeth $(n=7)$, further unsuccessful orthodontic treatments $(n=6)$, alignment of the upper and lower labial segments $(n=1)$, orthodontic extrusion of the non-affected teeth $(n=1)$, overdentures $(n=1)$, and segmental osteotomy $(n=1)$. Five patients did not receive any treatment.

\section{PTH1R variants}

In 51 cases, PTH1R variants associated with PFE were reported. The data are presented in Table 2.

\section{Discussion}

This study was a systematic review investigating the reported clinical data for 314 patients diagnosed with PFE. To our knowledge, after the study by Ahmad et al. [12], this is the only systematic review on PFE. Baccetti reported a prevalence ratio of 1:2.25 (male: female) [1] for PFE. Despite the considerable sample size $(n=314)$, the sex was only reported in 27 cases ( 15 female and 12 male patients). From these data, it was not possible to determine whether the prevalence of PFE was different in women and men.

As per Frazier-Bowers et al. [9], PFE never affects the anterior teeth owing to the autosomal dominant mutations in PTH1R. In 118 cases, detailed information was available; premolars as well as molars were affected in 81 cases. No studies reported PFE in teeth other than molars and premolars, indicating that PFE only affects these teeth.

Deciduous teeth were impacted by PFE in only 38 patients, and 118 patients reported that their primary teeth were not affected by PFE. Hence, it can be said that PFE affects both dentitions.

In the study by Ahmad et al. [12], 13\% of the patients had hypodontia; this percentage was substantially higher than that in the normal population. In our review, out of 314 patients, only 5 were affected by hypodontia. The dental anomaly most commonly reported in our study was alteration in the root morphology $(n=11)$. The small number of reported cases indicates that additional dental anomalies like hypodontia are not significantly associated with PFE.

Since Decker et al. [8] identified a mutation in the PTH1R gene, 51 mutations of the PTH1R gene responsible for PFE were found in a review of the current literature. In addition to PFE, PTH1R mutation is also associated with four more clinically overlapping human disorders per the type of mutation: Jansen's metaphyseal chondrodysplasia, Eiken syndrome, which is a skeletal disorder, Blomstrand osteochondrodysplasia, and Ollier disease [14]. Nevertheless, it is unclear whether only mutations in the PTH1R gene cause PFE because not all patients with PFE had the PTH1R mutation [18]. It has been reported that viral attacks on the nerve paths or mumps may lead to the development of dental disorders as well as eruption [27, 28], but there is a lack of evidence in this regard. 


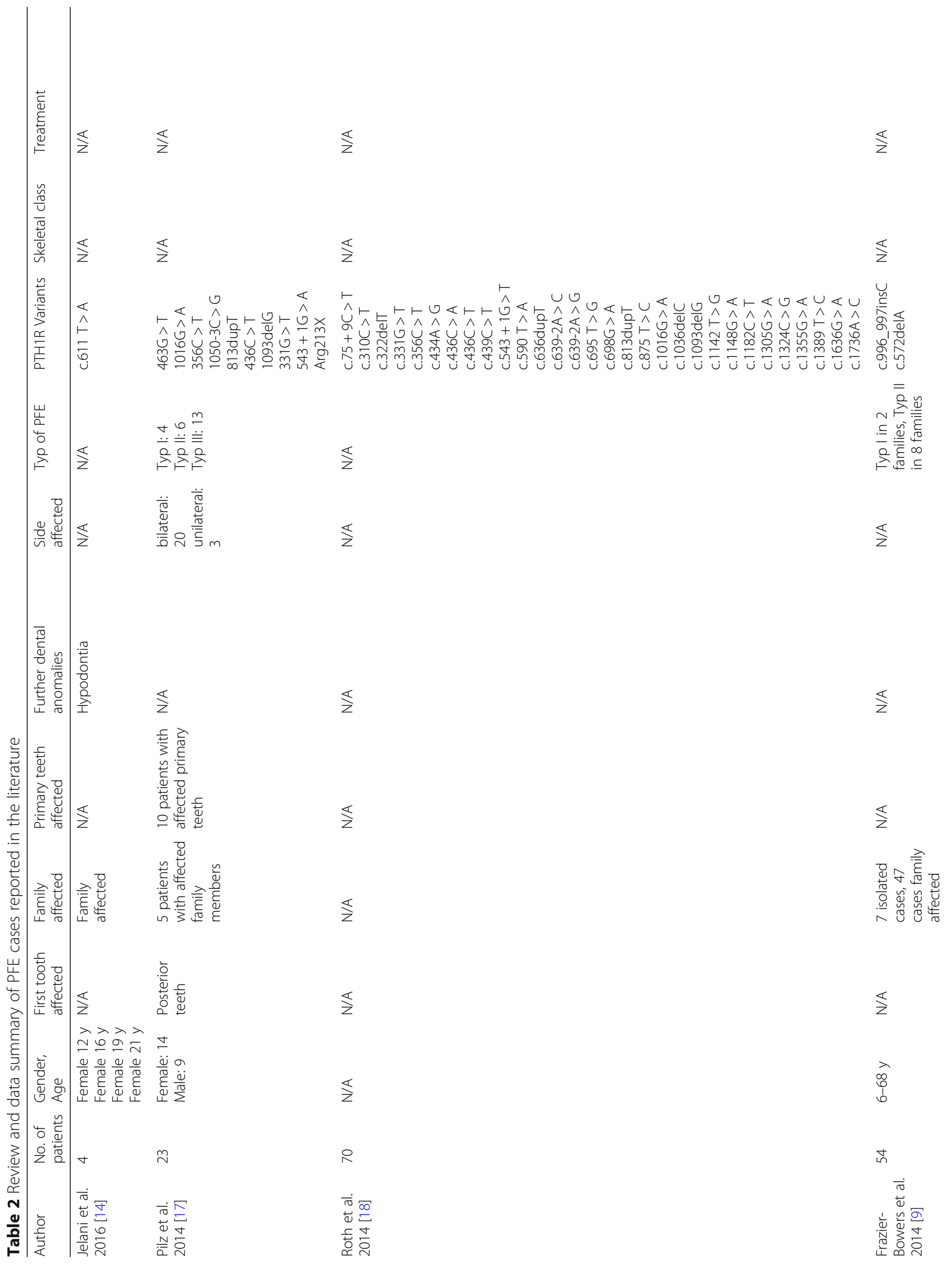




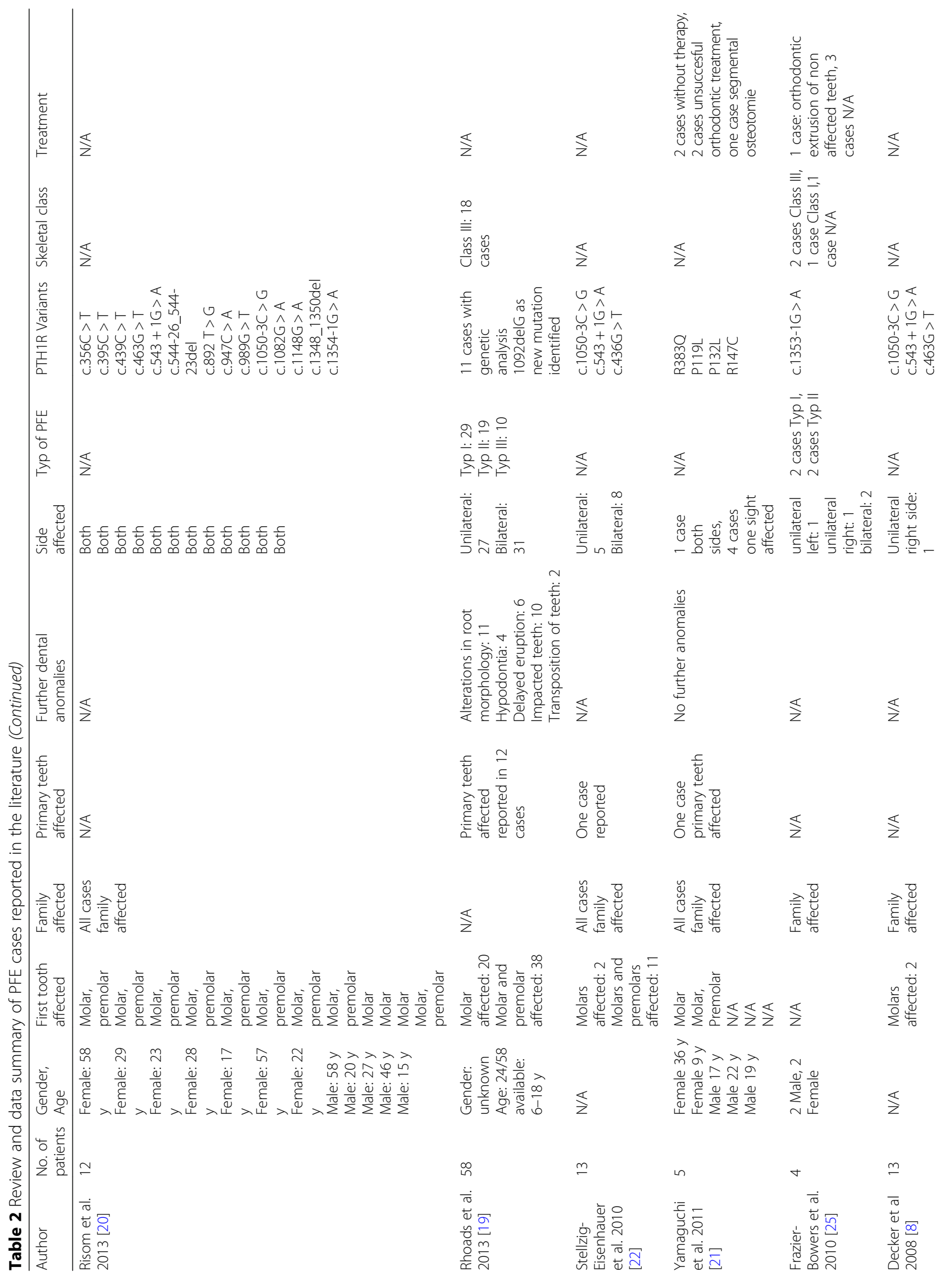




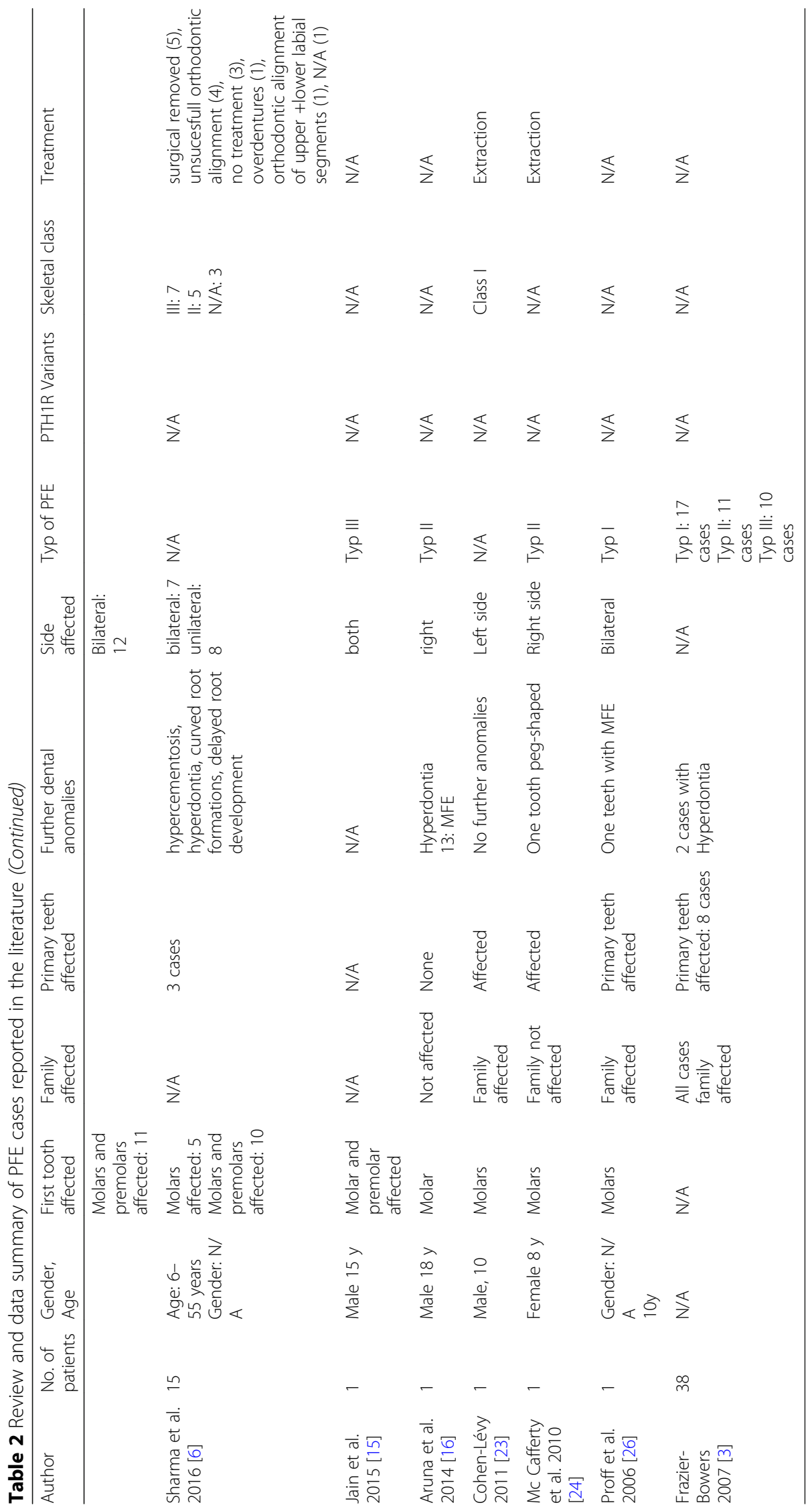


Based on their study conducted in 2006, Ahmad et al. [12] conclude that a strong family history of PFE is a risk factor for developing PFFE, while Rhoads et al. reported that the previously reported prevalence rates of $10 \%$ to $40 \%$ for familial PFE cases are expected to increase as more information about the genetic makeup of patients diagnosed with PFE is obtained [19]. In our systematic review, 143 patients were reported to have a family history of PFE, while 27 patients had no family history of PFE. In 144 cases, no further information about the family members was available. Considering the 170 patients who gave further detailed information about the occurrence of PFE among their family members, almost $85 \%$ had a family member affected by PFE. Absence of PFE in the family history may be explained by spontaneous mutations [3].

Sometimes, it is difficult to distinguish PFE from other eruption disorders like ankylosis. Based on the results of this study, the ratio of bilateral or unilateral side being affected by PFE is 1.8:1. This could help differentiate PFE from isolated ankylosis, which affects usually only one arch [19]. However, further significant data are needed to confirm these results.

An infraoccluded supracrestal first molar seems to be the hallmark of PFE [19], and all teeth distal to the most mesial tooth are affected by infraocclusion and PFE [2]. Nevertheless, in some patients, it is unclear whether PFE is present or not. If a patient is suspected of having PFE and other eruption failures like MFE, isolated ankylosis or systemic/syndromic disorders must be excluded, and a genetic test for mutations in the PTH1R gene must be recommended to prevent incorrect treatment [25]; especially, orthodontic extrusion must be avoided as it can lead to ankylosis.

Treatment provision was only reported in 22 cases. As per the study by Proffit and Frazier [3] the practice of extracting the teeth affected by PFE is correct. Generally, treatment depends on the patient's age and the clinical situation [23]. In young patients, direct or indirect composite build-ups could ensure occlusal stability and preserve alveolar bone level until an implant placement is possible [29]. In adult patients with only mild infraocclusion, no treatment is required; however, regular observation is necessary [23]. In addition, prosthetic build-ups with a maximum height of $5 \mathrm{~mm}$ can be used to minimize the lateral infraocclusion [30].

In addition to the extraction of teeth affected by PFE, further surgical measures such as segmental osteotomy to surgically reposition the teeth into occlusion [3] and distraction osteogenesis to correct the extreme posterior open bite may also be performed [31], however, few successful cases have been reported. Often, a removable prosthesis is the only feasible therapeutic option [32]. All in all, only a few cases describing treatment options were reported. Therefore, treatment options should be evaluated by clinical studies in future.

\section{Conclusions}

Infraocclusion of the posterior teeth, especially if both sides are affected, seems to be the hallmark of PFE. If a patient is affected by PFE, all teeth distal to the most mesial tooth are also affected by PFE. Primary teeth can also be impacted; however, this may not necessarily occur. If PFE is suspected in a patient, a genetic test for mutation in the PTH1R gene should be recommended prior to any orthodontic treatment to avoid ankylosis. Treatment options must consider the patient's age and the clinical situation, and they must be evaluated individually.

\section{Abbreviations}

MFE: Mechanical failure of eruption; PFE: Primary failure of eruption

\section{Acknowledgements}

We acknowledge support by Open Access Publication Fund of University of Muenster.

Funding

This research did not receive any specific grant from funding agencies in the public, commercial, or not-for-profit sectors.

\section{Availability of data and materials}

The datasets supporting the conclusions of this article are available at the Department of Cranio-Maxillofacial Surgery, University Hospital Münster Germany.

\section{Authors' contributions}

$\mathrm{MH}, \mathrm{LH}$ reviewed the literature. SJ and JK helped in the interpretation of data. $\mathrm{MH}, \mathrm{LH}, \mathrm{JK}$ and SJ participated in design, and drafting of the manuscript. All authors read and approved the final manuscript.

\section{Ethics approval and consent to participate}

The ethical approval for this study was obtained from the ethical review committee (Ref. no. 2017-372-f-N), Ethikkommission der Ärztekammer Westfalen-Lippe und der Westfälischen Wilhelms-Universität, Münster, Germany.

\section{Consent for publication}

Not applicable.

\section{Competing interests}

The authors declare that they have no competing interests.

\section{Publisher's Note}

Springer Nature remains neutral with regard to jurisdictional claims in published maps and institutional affiliations.

\section{Author details}

'Department of Cranio-Maxillofacial Surgery, Research Unit Rare Diseases with Orofacial Manifestations (RDOM), University Hospital Münster, Albert-Schweitzer-Campus 1, Gebäude W 30, D-48149 Münster, Germany. ${ }^{2}$ Department of Orthodontics, Faculty of Health, School of Dentistry, Witten/ Herdecke University, Alfred-Herrhausen-Strasse 44, 58455 Witten, Germany. 
Received: 4 October 2017 Accepted: 9 March 2018

Published online: 15 March 2018

\section{References}

1. Baccetti T. Tooth anomalies associated with failure of eruption of first and second permanent molars. Am J Orthod Dentofac Orthop. 2000; 118(6):608-10.

2. Proffit WR, Vig KW. Primary failure of eruption: a possible cause of posterio open-bite. Am J Orthod. 1981:80:173-90.

3. Frazier-Bowers SA, Koehler KE, Ackerman JL, Proffit WR. Primary failure of eruption: further characterization of a rare eruption disorder. Am J Orthod Dentofac Orthop. 2007;131:578.

4. Raghoebar GM, Boering G, Vissink A. Clinical, radiographic and histological characteristics of secondary retention of permanent molars. J Dent. 1991; 19(3):164-70.

5. Raghoebar GM, Boering G, Vissink A, Stegenga B. Eruption disturbances of permanent molars: a review. J Oral Pathol Med. 1991;20:159-66.

6. Sharma G, Kneafsey L, Ashley P, Noar J. Failure of eruption of permanent molars: a diagnostic dilemma. Int J Paediatr Dent. 2016;26:91-9.

7. Raghoebar GM, Boering G, Jansen HW, Vissink A. Secondary retention of permanent molars: a histologic study. J Oral Pathol Med. 1989;18:427-31.

8. Decker E, Stellzig-Eisenhaurer A, Fiebig BS, et al. PTHR1 loss-of-function mutations in familial, nonsyndromic primary failure of tooth eruption. Am Hum Genet. 2008:83:781-6.

9. Frazier-Bowers SA, Hendricks HM, Wright JT, Lee J, Long K, Dibble CF, et al Novel mutations in PTH1R associated with primary failure of eruption and osteoarthritis. J Dent Res. 2014;93(2):134-9.

10. Fukushima H, Jimi E, Kajiya H, Motokawa W, Okabe K. Parathyroid-hormonerelated protein induces expression of receptor activator of NF-\{kappa\}B ligand in human periodontal ligament cells via a cAMP/protein kinase Aindependent pathway. J Dent Res. 2005;84:329-34

11. Ouyang H, McCauley LK, Berry JE, Saygin NE, Tokiyasu Y, Somerman MJ. Parathyroid hormone-related protein regulates extracellular matrix gene expression in cementoblasts and inhibits cementoblast-mediated mineralization in vitro. J Bone Miner Res. 2000;15:2140-53.

12. Ahmad S, Bister D, Cobourne MT. The clinical features and aetiological basis of primary eruption failure. Eur J Orthod. 2006;28:535-40.

13. Moher D, Liberati A, Tetzlaff J, Altmann DG, The PRISMA Group. Preffered reporting items for systematic reviews and Meta analyses: the PRISMA statement. PLoS Med. 2009;6(7):e1000097.

14. Jelani M, Kang C, Mohamoud HS, Al-Rehaili R, Almramhi MM, Serafi R, et al. A novel homozygous PTH1R variant identified through whole-exome sequencing further expands the clinical spectrum of primary failure of tooth eruption in a consanguineous Saudi family. Arch Oral Biol. 2016;67:28-33.

15. Jain U, Kallury A, Rao DD, Bharti HV. Primary failure of eruption (PFE). BMJ Case Rep. 2015;1:2015.

16. Aruna U, Annamalai PR, Nayar S, Bhuminathan S. Primary failure of eruptiona case report with cone beam computerized tomographic imaging. J Clin Diagn Res. 2014;8(4):14-6.

17. Pilz P, Meyer-Marcotty P, Eigenthaler M, Roth H, Weber BH, StellzigEisenhauer A. Differential diagnosis of primary failure of eruption (PFE) with and without evidence of pathogenic mutations in the PTHR1 gene. J Orofac Orthop. 2014;75(3):226-39.

18. Roth $H$, Fritsche LG, Meier C, Pilz P, Eigenthaler M, Meyer-Marcotty $P$, et al. Expanding the spectrum of PTH1R mutations in patients with primary failure of tooth eruption. Clin Oral Investig. 2014;18(2):377-84.

19. Rhoads SG, Hendricks HM, Frazier-Bowers SA. Establishing the diagnostic criteria for eruption disorders based on genetic and clinical data. Am J Orthod Dentofac Orthop. 2013;144(2):194-202.

20. Risom L, Christoffersen L, Daugaard-Jensen J, Hove HD, Andersen HS, Andresen BS, et al. Identification of six novel PTH1R mutations in families with a history of primary failure of tooth eruption. PLoS One. 2013;8(9): e74601.

21. Yamaguchi T, Hosomichi K, Narita A, Shirota T, Tomoyasu Y, Maki K, et al Exome resequencing combined with linkage analysis identifies novel PTH1R variants in primary failure of tooth eruption in Japanese. J Bone Miner Res. 2011:26(7):1655-61.

22. Stellzig-Eisenhauer A, Decker E, Meyer-Marcotty P, Rau C, Fiebig BS, Kress W, et al. Primary failure of eruption (PFE)-clinical and molecular genetics analysis. J Orofac Orthop. 2010;71(1):6-16.
23. Cohen-Levy J. Ankylosis of permanent first molars: genetics or environment? A case report of a discordant twin pair. Int Orthod. 2011:9(1):76-91.

24. Mc Cafferty J, Al Awadi E, O'Connell AC. Case report: management of severe posterior open bite due to primary failure of eruption. Eur Arch Paediatr Dent. 2010;11(3):155-8.

25. Frazier-Bowers SA, Simmons D, Wright JT, Proffit WR, Ackerman JL. Primary failure of eruption and PTH1R: the importance of a genetic diagnosis for orthodontic treatment planning. Am J Orthod Dentofac Orthop. 2010;137(2):160.

26. Proff $P$, Bayerlein T, Fanghänel J, Allegrini S Jr, Gedrange T. Morphological and clinical considerations of first and second permanent molar eruption disorders. Ann Anat. 2006:188(4):353-61.

27. Bang E, Kjær I, Christensen LR. Etiological aspects and orthodontic treatment of unilateral localized arrested tooth development combined with hearing loss. Am. J. Orthod. Dentofac. Orthop. 1995;108:154-61.

28. Becktor KB, Bangstrup MI, Rølling S, Kjær I. Unilateral primary or secondary retention of permanent teeth and dental malformations. Eur J Orthod 2002:24:205-14.

29. Sehra B, Johnson J. The prosthetic Management of an Infra-Occluded First Permanent Molar: case report. Dent Update. 2016;43(5):482-4,486.

30. Mullally $\mathrm{BH}$, Blakely D, Burden DJ. Ankylosis: an orthodontic problem with a restorative solution. Br Dent J. 1995;179:1126-30.

31. Kater WM, Kawa D, Schafer D, Toll D. Treatment of posterior open bite using distraction osteogenesis. J Clin Orthod. 2004;38:501-4.

32. Siegel SC, O'Connell A. Oral rehabilitation of a child with primary failure of tooth eruption. J Prosthodont. 1999:8:201-7.

\section{Submit your next manuscript to BioMed Central and we will help you at every step:}

- We accept pre-submission inquiries

- Our selector tool helps you to find the most relevant journal

- We provide round the clock customer support

- Convenient online submission

- Thorough peer review

- Inclusion in PubMed and all major indexing services

- Maximum visibility for your research

Submit your manuscript at www.biomedcentral.com/submit
Biomed Central 